\title{
Revisiting the role of standardization and patenting of scintillation engineering in innovation processes
}

\author{
Yu.Danylenko ${ }^{1}$, V.Lyubynskiy ${ }^{1}$, An.Pavlova ${ }^{2}$ \\ ${ }^{1}$ Institute for Scintillation Materials, STC "Institute for Single Crystals", \\ National Academy of Sciences of Ukraine, \\ 60 Nauky Ave., 61001 Kharkiv, Ukraine \\ ${ }^{2}$ Ukrainian Engineering Pedagogics Academy, \\ 16 Universitetskaya Str., 61003 Kharkiv, Ukraine
}

Received December 20, 2017

\begin{abstract}
The analysis of impact of standardization and patenting of scintillation engineering on innovation processes is carried out and a model of their interaction is developed.

Keywords: scintillation engineering, standardization, innovation, patenting, influence.

Проведен анализ влияния стандартизации и патентования для сцинтилляционной техники на инновационные процессы и разработана модель их взаимодействия.

До питання про роль стандартизації та патентування сцинтиляційної техніки в інноваційних процесах. Ю.Даниленко, В.Любінський, А.Павлова.

Проведено аналіз впливу стандартизації та патентування для сцинтиляційної техніки на інноваційні процеси та розроблено модель їх взаємодії.
\end{abstract}

\section{Introduction}

Today, the development of companies of all forms of ownership is achieved generally due to innovation processes, which are significantly influenced by the global economy and competitive struggle in the global market [1].

By now standardization is essential by virtue of the fact that it combines together the engineering solution, provides cooperation between different branches of industry and the effective adoption of technology in the production[2].

The question of mechanisms of influence of standards on the innovation process was considered by Knut Blind, Peter Swann, Endry Grotnes, Rey Lambert et al.

The standards can be as informative and promote innovation, as be restraining and restrict them. However, any standards can include side by side both these effects. The standards for advanced companies are a source of information that helps them create innovation. Sometimes the standards requirements may restrict innovation activities for some companies, although these restrictions do not necessary prevent the innovation process. In fact, these "informative" and "obstructed" effects, as a rule, occur together. The question of using standards depends only from companies[3].

The application of measuring systems for a manufacturer allows to create a high quality product and to prove that the characteristics of an innovative product meet the standardized requirements. Author explains that the most common cause of market failure from the innovative product is asymmetric information between buyers and sellers. Due to the absent of the relevant standardthe buyer can't distinguish good quality products from bad quality ones and does not 
buy them, or purchases a low-quality product. In this case, the company can develop its own measuring devices to demonstrate the superiority of their innovative products over others [4].

The standardization can particularly contribute to the innovation in three areas. At first, it shows both standardization as a technology transfer channel and the standards as enablers and facilitators for research. The second area focuses on the difficult but promising issue of transferring intellectual property rights (IPR) into the standards, and shows how this can be beneficial both for the IPR holders and standards implementers. The third newly emerging field concerns the role of standards and standardization in procurement processes, which are more and more forced to address and promote the innovations [5].

Anticipatory standardization, which takes advantage of knowledge, IPR and technical know-how, contribute to creation of the new innovations in the mobile telecommunications domain. The author attributes it with systemic character of the technology standardization and the lack of participants that can provide all parts of the value chain for creating a product. Such a systemic character leads to the companies collaboration and to the open innovation process to provide the complete system for obtaining the new products. Companies get the IPR for their inventions and technical know-how, and, together with other companies, they use their shared knowledge to generate the new specifications in a cooperative environment. The author considers the anticipatory standardization as an open innovation model, which allows us to consider the process of standardization from another perspective. That is, standardization isn't the place where firms choose technology in retrospect, but it's an arena where innovations take place because the standardized technology has a systemic character and corresponds to the current level of science [6].

The Innovation Horizon 2020 program [7] focuses on the diffusion of innovation through scientific publications and creation of the IP, in other word, on the full employment of the potential of research infrastructures.

The purpose of this paper is to study the influence of standards mechanisms and objects of intellectual property on the innovative processes in scintillation technique.

Currently, various scintillation crystals are widely used in scintillation detectors in many fields of science, engineering, medicine. Also scintillation materials are widely used in scientific experiments on high-energy physics, for example, in scintillation detectors in Hadron Calorimeters for the new generation of accelerators such as LHC CERN (Switzerland), etc.

For example, each manufacturer of the scintillation detectors offers its own production nomenclature (identification) and presents, in the first place, their trademarks and introduces their own abbreviations. The nomenclature of scintillators and scintillation detectors is quite complicated, and it may include the following characteristics: detector type; scintillator material, geometry and dimensions; material of housing and window; type and dimensions of the photomultiplier tube or photocathode; the availability of additional electronic devices and some other characteristics. Different manufacturers offer different content and different order of characteristics designations in the identifiers of their products. It is difficult for a customer to perceive the meaning of symbols in these identifiers. The situation can be improved through introducing a uniform system of nomenclature (identification) of the scintillators and scintillation detectors. For this purpose it is advisable to use designations of separate parameters in a strict order, guided by a principle: from the main parameters to the secondary ones. Development of international standard helps to introduce the uniformity into the system of nomenclature (identification) of the scintillators and scintillation detectors, as well as will facilitate the perception of this system and correct selection of the products by customers [8].

\section{Exploring}

As part of this work, the following international standards were developed in subcommittee of TC45 of IEC SC 45B "Radiation protection instrumentation":

The purpose of development of International Standard IEC 60412:2014 [8] was to standardize the scintillators nomenclature to contain the maximum number of characteristics. Despite the fact that production of scintillators has existed for more than 50 years, there was no single nomenclature of the scintillators. Every company had its own nomenclature, which caused ambiguity and some difficulties in interpretation of the products for customers. Analysis of the scintillation nomenclature of used by leading companies was carried out and uniform 
requirements for the scintillators nomenclature were developed. Also this standard gives guidelines for scintillation detectors and scintillators nomenclature (identification) and standard dimensions of the scintillators in order to facilitate the interchangeability of the scintillators without a container. It is applicable to all types of solid organic and inorganic scintillators used in detectors for scintillation counting and spectrometry. Today, some companies use this nomenclature.

To establish the basic parameters of housed scintillator such as light output and intrinsic resolution the International standard IEC 62372:2006 [9] was developed. It is applicable to housed scintillators for registration and spectrometry of alpha-, beta-, gamma-, X-ray and neutron radiation and specifies the requirements for equipment and methods of defining the basic parameters of the housed scintillators, such as: direct method for the light output measurement for scintillators on the base of any given scintillation material; the method of comparison with the working standard for scintillators on the base of the same scintillation material with the working standard.

The international standard IEC 60462:2010 [10] establishes test procedures for photomultiplier tubes (PMT) which are used in scintillation and the Cherenkov counting, both in the detection and analysis of ionizing radiation and for other applications. The necessity of this standard is related to establishment of the standard test procedures for measurements of these characteristics which may have the same significance for for all manufacturers and users.

Due to development of the international standard IEC 61435:2013 [11] the terminology and test methods for measurements of basic characteristics of high-purity germanium crystals such as electrically active impurity concentrations, deep-level impuritycentre concentration and crystallographic quality of crystals were determined. The high-purity germanium crystals are used for radiation detectors for gamma-rays and $\mathrm{X}$-rays.

The methods of calibration and routine tests of scintillation detector systems for the measurement of gamma-ray energies and emission rates of radionuclides and the assay of radioactivity were specified by the International standard IEC 61453:2007 [12] which is applicable for scintillation detector systems based on inorganic scintillators for photon measurements.
At the end of the $R \& D$ the patent rights for new innovation products were obtained by the Institute for Scintillation Materials of the National Academy of Sciences of Ukraine. For example, compositions of radiation-resistant plastic scintillators were patented [13-15].These new innovative products are intended for use in conditions of the high radiation loads for researches on the high-energy particle beams in highpower accelerators and are used in detector of CERN Large Hadron Collider (LHC). Developed plastic scintillators have new properties that meet the requirements of the modern physical experiment. Unique detectors on their basis for resonant international projects in the field of high energy physics were created. These scintillators took their worthy place in the world market.

\section{Results and discussion}

The research of application of the abovementioned international standards and objects of intellectual property allows us to separate the following mechanisms of influence of the standards on the innovative processes, which include the following:

- Developed standards on technology and test methods for scintillation engineering promote their effective distribution and appearance into the market of new users, which are a powerful force for innovation.

- The standard on the nomenclature of scintillators allowed to reduce the information inconsistency for customers of scintillation products and to regulate diversity of these products.

- The product quality control standards permit to increase the customer satisfaction and consumer demand, which influences the growth rate of production and allows to reach the limit conditions for creation of innovation.

The conducted research shows, that sometimes standardization and innovation are seen as contradictive processes. On the one hand, the creation of innovations demands novelty and exclusivity, whereas standardization seeks for predictability and unification. On the other hand, standardization makes in an important contribution to the innovation and it gives a possibility to prove that technical characteristics of the new products and services are according to the global requirements, if and only if when the standards include know-how and IP.

In scintillation engineering when scientific progress has very high growth rates, 
Yu.Danylenko et al. / Revisiting the role of ...

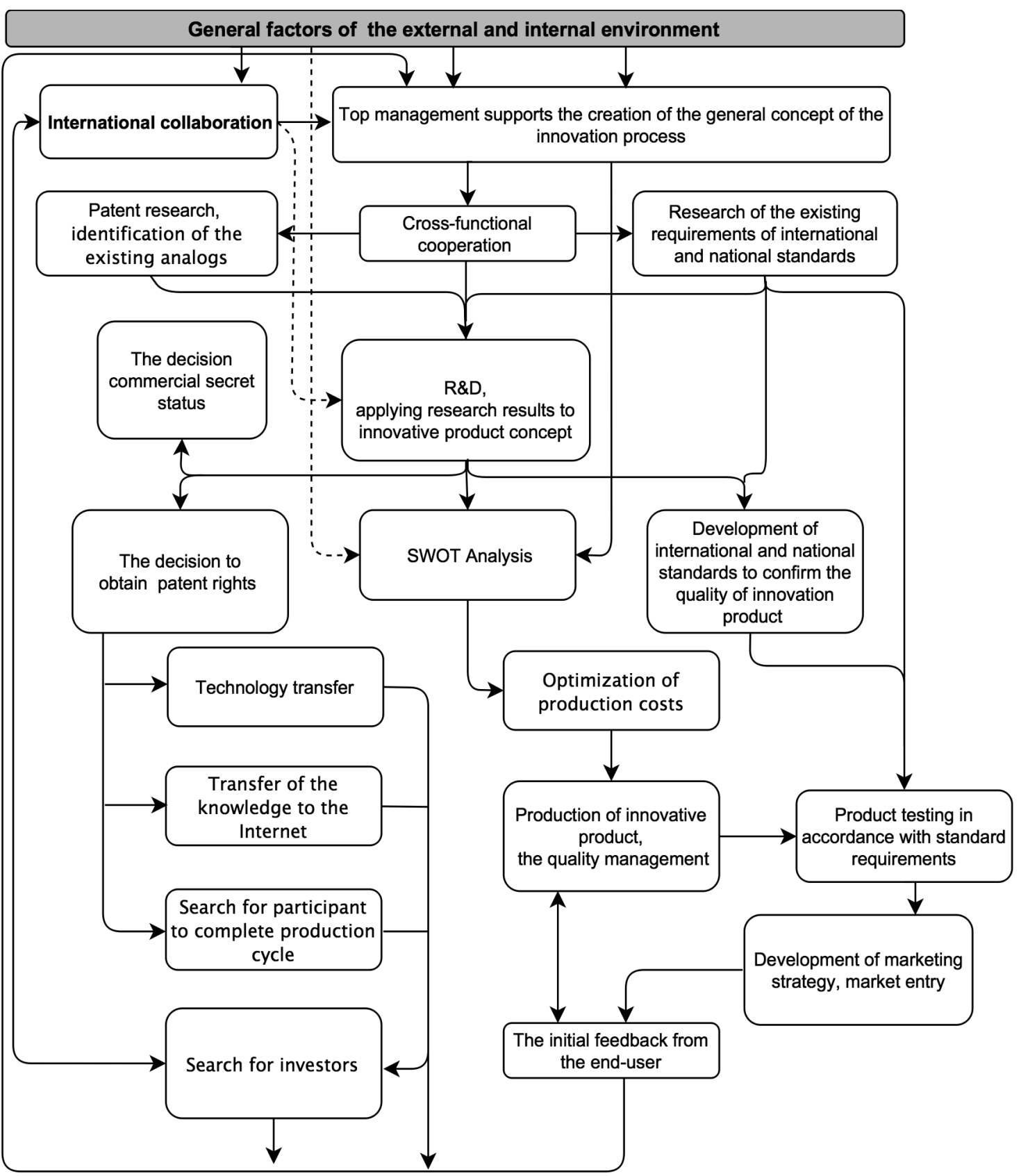

Fig.. Analyzing the process of developing the international standards

anticipatory standardization of technologies and constructions, which includes getting rights for intellectual property objects for their inventions, knowledge and technical know-how, is systemic in the case of absence of possibility to provide the creation action cycle of the product. Companies use their knowledge to create the new IP in common surroundings and that leads to the open innovation process and getting the new innovation products through competition and, as consequence, to the new IP. The patents worldwide are indispensable sources of information for the level of development of the science and technology.

Analyzing the process of developing the international standards and obtaining rights for the intellectual property, a model of the impact of various factors on the process of creating an innovative product was developed (see Fig.).

First of all,the general factors of the ambient environment and market demand for in this product or service have a big impact. If the product has entered the market prematurely, it will not be find its consumer 
and will not accepted by market. The understanding of the company management in the necessity of the innovative processes is also very important. The coordination between of all departments of the company and their realization that the successful innovation process is depended on their ability to be flexible and to change their strategy under the environmental influence.

Before starting the research work (R\&D), it is necessary to carry out a patent research, identify the existing analogies, and to clearly know the existing requirements of the international and national standards.

At the end of the research work the company management decides to patent the innovative product as an invention or to introduce it as a commercial secret.

In the case the requirements for this innovation product are not yet standardized or the created product has better characteristics than the existing analogies, or the requirements of present standards are already out-of-date, then it's necessary to develop the international or national standards to confirm that innovation product meets the safety and necessary technical requirements. This will allow to prove to the buyer the created product is high quality and will be in demand on the world market.

A risk assessment calculate the production risks of the innovation product and introduction of the product to the market are made upon completing the research to minimize the product price. Also the product for conformity with the standard requirements is tested to prove the manufactured product is homogeneous and has high quality.

This above-mentioned innovation process starts immediately when the product is appeared on the market. This constant complete cycle may help the company to survive during the market competition.

\section{Conclusions}

Developed standards for the scintillation engineering, focused on innovation and understanding of the significance of obtaining intellectual property rights, are important for the perspective development of the company, introduction of the innovative technologies and the successful introduction of the innovation products into the market.

Using the anticipating standardization at the level of scientific research timely get- ting the intellectual property rights objects contribute to creation of the new innovations and introduction of the new innovative processes.

\section{References}

1. B.V.Grinyov, Yu.A.Danylenko, O.V.Zhikhareva et al., Standardization. Certification. Quality, 3, 13 (2013) [in Ukrainian].

2. B.V.Grinyov, V.R.Lyubinskiy, Yu.A.Danylenko et al., Science and Innovation, 10, 50 (2014).

3. G.M.P Swann, The Economics of Standardization - An Update Report for the UK Department of Business, Innovation and Skills (BIS), London, UK: Innovation Economics Limited (2010).

4. R.Lambert, Economic Impact of the National Measurement System, Department for Business, Innovation and Skills, London, UK (2010).

5. K.Blind, The Impact of Standardization and Standards on Innovation. Compendium of Evidence on the Effectiveness of Innovation Policy Intervention, Nesta Working Paper, No.13/15 (2013).

6. Open IT-Based Innovation: Moving Towards Cooperative IT Transfer and Knowledge Diffusion. IFIP TC 8 WG 8.6.International Working Conference (Oct. 22-24, 2008, Madrid), Spain, 2008, v.287, p.343.

7. 7.2011a. From Challenges to Opportunities: Towards a Common Strategic Framework for EU Research and Innovation Funding, Green Paper COM(2011) 48. Brussels: European Commission. EC.

8. IEC 60412:2014 Nuclear Instrumentation Scintillationdetectors - Nomenclature (Identification) - Standard dimensions of scintillators -3 th ed.2014-09-24.

9. IEC 62372:2006 Nuclear Instrumentation Housed Scintillators - Measurement Methods of Light Output and Intrinsic Resolution2006-02-23.

10. IEC 60462:2010 Nuclear Instrumentation Photomultiplier Tubes for Scintillation Counting - Test Procedures - 2th ed. 2010-07-12.

11. IEC 61435:2013 Nuclear Instrumentation High-purity Germanium Crystals for Radiation Detectors - Measurement Methods of Basic Characteristics - 2th ed. 2013-08-12.

12. IEC 61453:2007 Nuclear Instrumentation Scintillation Gamma-ray Detector Systems for the Assay of Radionuclides - Calibration and Routine Tests - 2th ed. 2007-08-10.

13. U.A. Patent 113043 (2016).

14. U.A. Patent 113374 (2017).

15. U.A. Patent 113605 (2017). 